\title{
DESIGNING MONITORING TOOLS: METHODOLOGICAL APPROACHES TO EVALUATION OF REGIONAL BIOECONOMY STRATEGY IMPACTS
}

\author{
Filip TKÁČ; Danka MORAVČíKOVÁ \\ Department of Social Sciences, Faculty of Economics and Management, Slovak University of \\ Agriculture in Nitra, Nitra, Slovakia
}

\begin{abstract}
Bioeconomy can be considered one of the fastest-growing sectors of the economy, which brings new opportunities concerning economic growth and profit maximisation and sustainability, environment protection, and appropriate use of limited resources. Monitoring bioeconomy status should be an essential task for policy-makers and other stakeholders as business entities, non-governmental organisations, and others. Bioeconomy data are often unavailable because there is an insufficient distinction between bio-based and traditional industry in national statistics, which necessitates conjugating many data sources. For these reasons, it is crucial to define methodologies, which allows comparability. Such tools can find application in evaluating environmental, economic, social progress in the field of bioeconomy by different groups of stakeholders and granting the possibility to compare differences between countries or regions to enhance policies and support mechanisms. An undeniable advantage of the correct setting of monitoring tools is the possibility of performing scenario analysis and bringing the best solutions for developing the bioeconomy sector.

Purpose: The paper's main aim is to compare different approaches to monitoring bioeconomy strategies and evaluate their advantages and disadvantages concerning the availability of data sources.

Design/methodology/approach: The paper compares attitudes and approaches of different researchers on evaluating bioeconomy status and progress supplemented by comments. We work with varying sources, including research reports and papers.

Findings: The paper presents selected approaches to designing monitoring tools intended to evaluate regional bioeconomy status and impacts. The authors also discuss the differences and advantages versus disadvantages of these methodologies.

Research limitations: The paper introduces methodological approaches into bioeconomy evaluation as the initial research stage focused on evaluating bioeconomy and ecoinnovations elements usage in European Countries.
\end{abstract}

Keywords: bioeconomy, evaluation, methodological approaches, regions, strategy

JEL: Q57

\section{Introduction}

Monitoring is the continuous and systematic generation of evidence on an intervention's activities and impacts over time. A monitoring system is a necessary and integral component of better regulation, assisting in determining whether a policy is being applied as expected on the ground, addressing any implementation issues with an intervention, and determining whether additional action is required to ensure that it can achieve its intended objectives (European Commission, 2017). 
The development of science and technology brings new opportunities that make the bioeconomy one of the fastest-growing sectors of the European economy. The interest in the bioeconomy is implied by global challenges, including ensuring food security, sustainable management of natural resources, reducing dependence on nonrenewable resources, and mitigating or adapting to climate change. On the other hand, many countries emphasise the importance of the bioeconomy but do not have a comprehensive strategy for its development and implementation (Wozniak; Twardowski, 2017).

Around 50 countries have incorporated the bioeconomy into their economic and innovation plans, demonstrating intent and commitment but falling short on detail. As a result, a single system that examines the significant policy implications of a bioeconomy would be valuable (OECD, 2018) and is necessary to identify and monitor impacts and role towards other sectors (Loizou et al., 2019).

The bioeconomy can be considered a cross-sectoral living organism, and therefore it is not possible to define a single correct way of measuring it. The choice of the specific methodology and indicators examined depends primarily on the objectives that the researcher explains, whether it is only an ex-post analysis or comparison, or the creation of public policy proposals, or measures to improve the position of the bio-based sectors.

The paper summarises selected approaches of research teams, emphasising the identification of recommended indicators, their strengths and weaknesses.

\section{Literature review / Research Background}

The term bioeconomy includes the production, use, and protection of biological resources, including related knowledge, science, technology, and innovation, to provide information, products, processes, and services in all sectors of the economy focused on a sustainable economy (Global Bioeconomy Summit, 2018).

Another definition is provided by BECOTEPS (2011), which states that the term bioeconomy refers to the sustainable production and conversion of biomass into various products, including food, health, industry, and energy, with biomass encompassing any biological material (originating from agriculture, forestry, fishing), which is used either as a product itself or as a raw material in future production.

The European Commission (2012) defines the bioeconomy as those parts of the economy that use renewable biological resources from land and sea - such as crops, forests, fish, animals, and microorganisms to produce food, materials, and energy.

Achieving the desired success in the bioeconomy requires the integration of public policy orientations, in particular in the following critical areas of BECOTEPS (2011):

- Investing in relevant research areas and promoting multidisciplinarity.

- Promoting innovation to ensure the commercialisation of knowledge.

- Promoting entrepreneurship in the bioeconomy as a desirable career option.

- Ensure a skilled workforce for individual sectors of the bioeconomy through secondary and tertiary education. 
- Simplified legislative frameworks supporting innovation.

- Appropriate forms of communication with the involved public to develop social recognition of development and innovation.

There are many definitions of the bioeconomy, but they show similarities, emphasising economic production and a broad cross-sectoral focus. The benefits and opportunities associated with the development of an advanced bioeconomy in Europe bring great optimism. On the other hand, we may encounter several risks and the need for compromises. To increase the competitiveness and sustainability of the bioeconomy, attention needs to be paid to participatory governance involving the general public and critical stakeholders in the open, informed dialogue and to the commitment of governments and industry to sustainable innovation (McCormick; Kautto, 2013).

Moreover, bioeconomy is interconnected with several other terms, including biobased economy, green economy and circular economy, while circular economy and bioeconomy can be considered synergic concepts (Kardung et al., 2019).

Measuring the bioeconomy is still in its infancy and is fraught with methodological difficulties. Because the bioeconomy spans across industries, it cannot be classified as a specific economic sector. Economics must catch up to the reality of the bioeconomy. A thorough economic assessment necessitates knowledge of bioeconomy resources, components, and product streams. It is necessary to improve data storage and analysis approaches that might allow bioeconomy prospects to be realised and assist drive policy (Wesseler, Braun et al., 2017). When official data is gathered, distinctions between bio-based and non-bio-based products are rarely made. However, production along bioeconomy supply chains and the implications for sustainability necessitate monitoring and assessment to enable informed policymaking (Jander et al., 2020).

The bioeconomy, as an industrial metabolism based on renewable resources, is distinguished by potential benefits for global sustainability, which are dependent on a variety of conditions and players. As a result, proper systematic monitoring of its progress is critical and intricately tied to the Sustainable Development Goals (SDGs) and various stakeholder expectations (Zeug et al., 2019). The EU bioeconomy's contribution to sustainable development is dependent on how it is implemented. A systemic monitoring system capable of dynamically linking human-environment interactions and many scales of analysis is required to verify that the EU bioeconomy transition fulfils overarching goals such as the Sustainable Development Goals. (O'Brien et al., 2017).

Identifying suitable sustainability indicators can be an essential step before developing and monitoring a sustainable bioeconomy (Bracco et al., 2019). Moreover, it is necessary to know driving forces, which provides essential information for monitoring activities (Kardung, 2019). On the other hand, unavailability of data, lack of granularity in available statistics respectively timeinconsistent data could cause gaps in Bioeconomy monitoring systems (Robert et al., 2020). 


\section{Methodology}

The paper is based on comparing selected research studies devoted to identifying indicators suitable to monitoring the bioeconomy.

The analysis is based in particular on the following publications:

- Public deliverables of the project "emPOWERing regional stakeholders for realising the full potential of European BIOeconomy."

- Public deliverables of the project "Monitoring the Bioeconomy."

- Articles wroten by Capasso \& Klitkou (2020), D'Adamo et al. (2020) and Jander et al. (2020)

\section{Results and discussion}

Monitoring and measuring the bioeconomy could be considered challenging but, on the other hand, a critical task. To develop a comprehensive tool or framework, it is necessary to establish a definition of the bioeconomy itself, which will be used to determining objects of investigation.

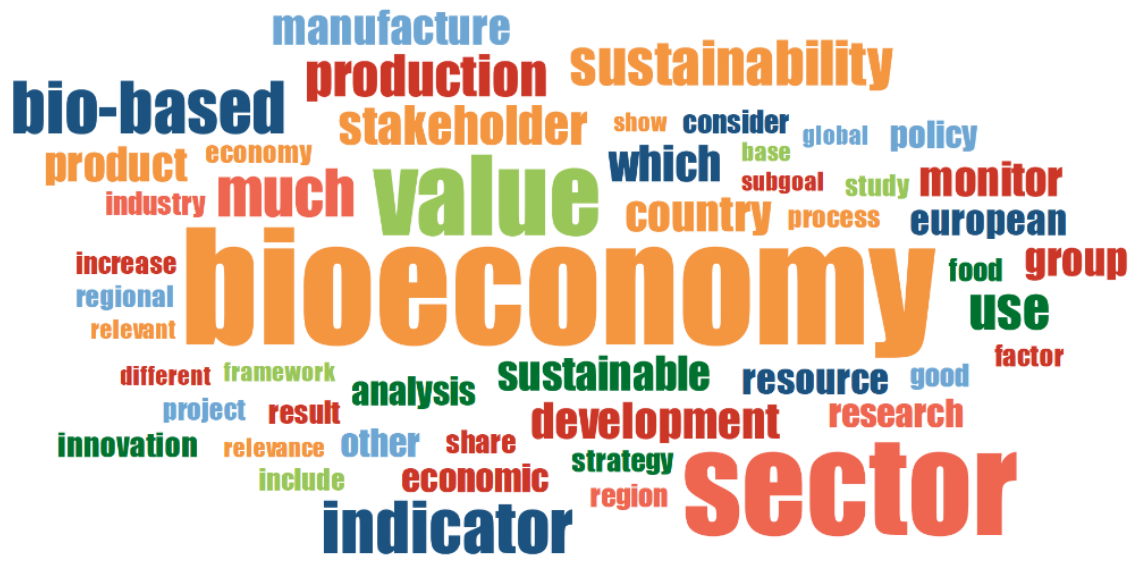

Figure 1. Terms connected to monitoring and evaluation of bioeconomy according to selected research studies

Source: own analysis based on studies mentioned in the methodology

As can be seen from Figure 1, there are many words interconnected with bioeconomy. If we take into account most frequent terms (with relative frequency above $0,5 \%$ ), which are present in all five analyzed documents we can conclude that monitoring bioeconomy should be focused on sectors $(1,58 \%)$, value $(1,07 \%)$, indicators $(0,69 \%)$, bio-based $(0,68 \%)$, sustainability $(0,58 \%)$, production $(0,56 \%)$, use $(0,54 \%)$ and stakeholders $(0,5 \%)$.

In the case of sectors is necessary to identify those, which are bio-based. At first glance, this may seem like a straightforward task. However, as Ronzon and M'Barek, (2018) pointed out, statistics are often based on NACE classification, which does not 
take into account explicit differentiation between bio-based and non-bio-based activities, while some sectors (as fishing and aquaculture, forestry, agriculture, manufacture of food beverages and tobacco, manufacture of paper) can be considered as bio-based, others are hybrid (using both biomass and other kinds of feedstock).

Sustainability can be considered an essential part and driver of bioeconomy potential. Therefore in evaluating and monitoring bioeconomy and potential, it is necessary to take it into account.

Under the term stakeholders, we can understand various groups of interested persons from policy-makers and scientists through entrepreneurs to the nongovernmental sector, including engaged citizen groups. It is necessary to include all these groups in the development of the bioeconomy to ensure its success. At the same time, stakeholders also have an important place in setting up monitoring tools, and according to Zeug et al. (2019), their participation is the most appropriate way to identify critical objectives.

Value, production, and use could be considered a subset of term indicators, in which selection is the primary and essential component of monitoring the performance and benefits of the bioeconomy, and we deal with it in the next part of this paper.

\section{Indicators necessary to monitoring bioeconomy}

Researchers bring diverse methodologies to choose indicators to establish models devoted to bioeconomy monitoring and evaluation.

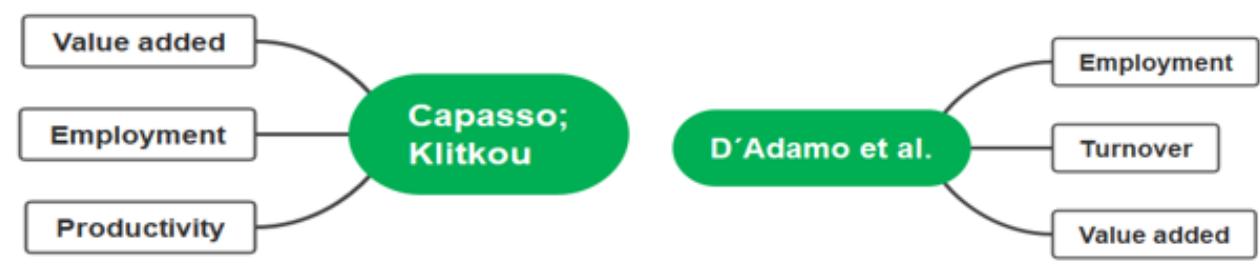

\section{Figure 2. Fundamental macroeconomic indicators to evaluate bioeconomy}

Source: based on studies written by Capasso, Klitkou (2020) \& D'Adamo et al. (2020)

Essential macroeconomic variables (Figure 2) brings the possibility to compare different countries respectively to evaluate the development of bioeconomy status in selected regions by time ex-post. Data availability devoted to employment, valueadded, turnover etc., is sufficient and in European Union also comparable thanks to Eurostat. On the other hand, the issue can be faced due to the identification of biobased parts in hybrid sectors as data on higher hierarchies of NACE are necessary. The main disadvantage of such a model can be considered the impossibility of a deeper analysis of the development of the bioeconomy and its potential, and thus the absent possibility to design policies towards the future. 


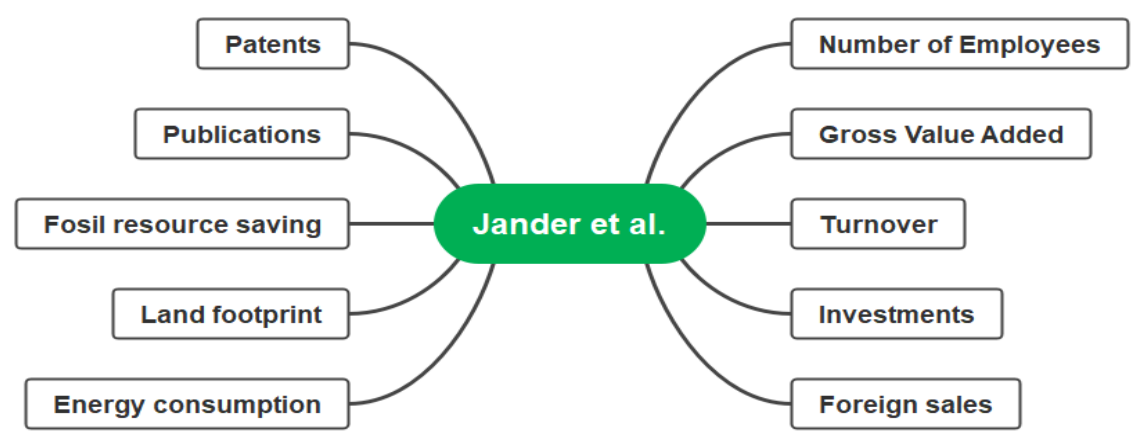

\section{Figure 3. Advanced macroeconomic indicators supplemented with primary environmental effects}

Source: based on a study written by Jander et al. (2020)

Jander et al. (2020) suggested supplementing essential macroeconomic variables (such as turnover, employment, value-added) with other investments and foreign trade, which allows a more detailed analysis of the impact of organic sectors on the region's economy. Moreover, the inclusion of science and research in biotechnology allows exploring the benefits and the status of the country concerning the bioeconomy. In addition, the authors recommend including environmental indicators in the monitoring tools (Figure 3), which brings added value in the possibility of evaluating the added value of bioeconomy development.

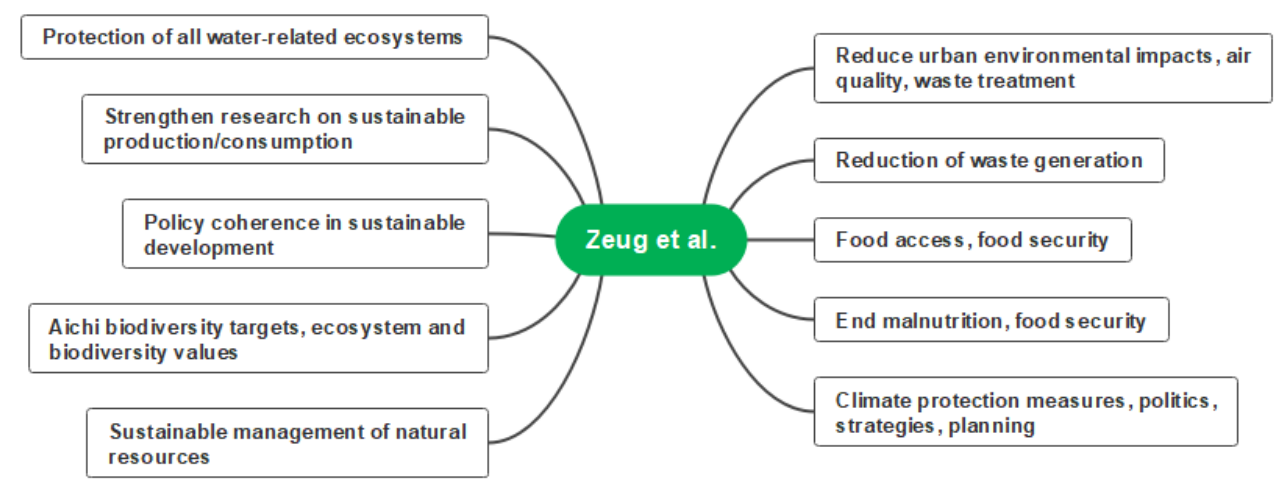

\section{Figure 4. Indicators based on Sustainable development goals}

Source: based on a study written by Zeug et al. (2019)

Another way to define indicators to evaluate and monitor effects and evaluation of bioeconomy is to connect with another development model. Zeug et al. (2019) suggest operationalising Sustainable Development Goals (at the level of sub-goals) while stakeholders identified corresponding components and key objectives (Figure 
4). Thich approach brings a certain amount of subjectivity due to the definition of specific relationships and connections between bioeconomy and SDGs and targets. On the other hand, the availability of data can be considered a positive, as the topic of SDG is given relatively extensive attention.

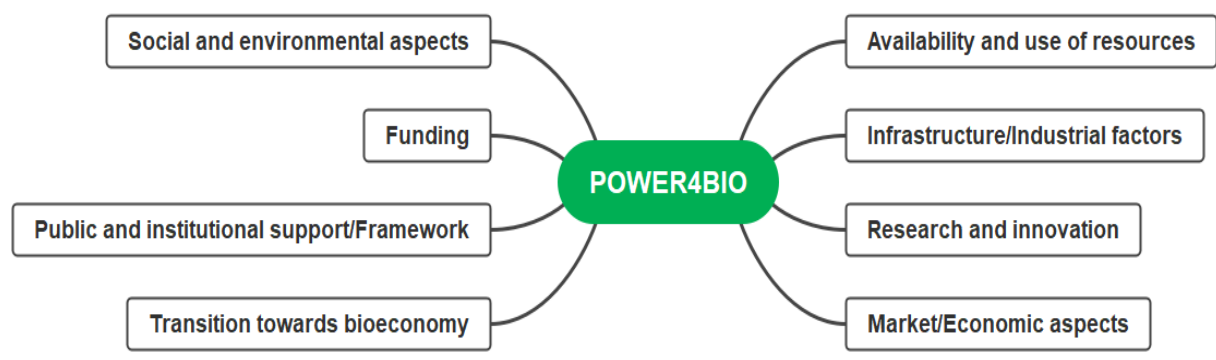

\section{Figure 5. Indicators according to the POWER4BIO research project}

Source: based on a study written by CIRCE et al. (2019)

The more comprehensive approach is provided by large-scale research projects focusing on the bioeconomy. One of the most current is the H2020 project called emPOWERing regional stakeholders for realising the full potential of the European BIOeconomy, which brings discursive view not only on defining appropriate indicators to measuring performance and monitoring bioeconomy. As can be clear from Figure 5, researchers suggest methodology, which brings quantitative macroeconomic aspects together with research situation in bio-based fields, social and environmental aspects that enrich the analysis of the state of support and predispositions to the development of the bioeconomy. Another research project was held under the H2020 scheme called Monitoring the Bioeconomy, which suggests a more quantitative approach focusing on food and nutrition security, sustainable natural resource management, dependence on non-renewable resources, mitigating and adapting to climate change, employment, and economic competitiveness (Kardung et al., 2019). Such a comprehensive approach makes it possible to assess the state and development of expost and comparison and brings discourse towards the creation of public policies supporting the development of the bioeconomy and sustainable development. On the other hand, the risk can be seen in the processing complexity of analyses based on such an approach and the availability or standardisation of obtaining quantitative data and the willingness of the institutions or persons concerned to cooperate with the research team.

\section{Conclusion}

Setting up bioeconomic monitoring systems can be considered a challenging task that does not lead to consistent results. Some approaches work exclusively with fundamental macroeconomic indicators, others are linked to sustainability assessment systems, and others combine large amounts of either quantitative or 
qualitative data. The lack of availability of statistical data and the issue of differentiation of bio-based production from individual sectors of the economy in national accounts statistics can be considered a clear problem in monitoring the bioeconomy.

It would be helpful to focus further analyses in this area on identifying the specific availability of data and consolidating them across regions and countries. It is also necessary to set up a standardised framework for evaluating qualitative indicators to ensure comparability.

\section{References}

1. BECOTEPS. (2012). The European Bio-economy in 2030, Delivering Sustainable Growth by addressing the Grand Societal Challenges: BECOTEPS \& Bio-Economy Technology Platforms.

2. Bracco, S., Tani, A., Çalıcıoğlu, Ö., Gomez, M., Juan, S., \& Bogdanski, A. (2019). Indicators to monitor and evaluate the sustainability of bioeconomy - overview of a prposed way forwrd. http://www.wipo.int/amc/en/mediation/rules

3. Capasso, M., \& Klitkou, A. (2020). Socioeconomic indicators to monitor Norway's bioeconomy in transition. Sustainability (Switzerland), 12(8). https://doi.org/10.3390/SU12083173

4. CIRCE (2019). Key performance indicators to evaluate regional bioeconomies.

5. D’Adamo, I., Falcone, P. M., \& Morone, P. (2020). A New Socio-economic Indicator to Measure the Performance of Bioeconomy Sectors in Europe. Ecological Economics, 176(May), 106724. https://doi.org/10.1016/j.ecolecon.2020.106724

6. Ecologic, P., \& Link, M. (2020). Sustainability and Participation in the Bioeconomy : A Conceptual Framework for BE-Rural. 818478.

7. European Commision. (2012). Communication from the Commision to the European Parliament, the Council, the European Economic and Social Committee and the Committee of the Regions. Innovationg for Sustainable Growth: A Bio-economy for Europe.

8. European Commision. (2018). A sustainable bioeconomy for Europe: strengthening the connection between economy, society and the environment. Luxemburg. ISBN 978-9279-94145-0.

9. European Commission. (2017). Better Regulation Guidelines SWD (Issue July).

10. European Commission. (n.d.). Chapter V Guidelines on monitoring. https://ec.europa.eu/info/sites/info/files/better-regulation-guidelines-monitoring.pdf

11. FAO. (2018). Assessing the contribution of bioeconomy to countries' economy. Rome. ISBN 978-92-5-130603-1

12. Global Bioeconomy Summit. (2018). Conference Report.

13. Jander, W., Wydra, S., Wackerbauer, J., Grundmann, P., \& Piotrowski, S. (2020). Monitoring bioeconomy transitions with economic-environmental and innovation indicators: Addressing data gaps in the short term. Sustainability (Switzerland), 12(11). https://doi.org/10.3390/su12114683

14. Kardung. (2019). Framework for measuring the size and development of the bioeconomy. 2019, 1-69.

15. Mccormick, Kes,. \& Kautto, Niina. (2013). The bioeconomy in Europe: An overview. In: Sustainability, vol. 5, no .6, pp.2589-2608. 
16. O’Brien, M., Wechsler, D., Bringezu, S., \& Schaldach, R. (2017). Toward a systemic monitoring of the European bioeconomy: Gaps, needs and the integration of sustainability indicators and targets for global land use. Land Use Policy, 66(December 2016), 162-171. https://doi.org/10.1016/j.landusepol.2017.04.047

17. Robert, N., Giuntoli, J., Araujo, R., Avraamides, M., Balzi, E., Barredo, J. I., Baruth, B., Becker, W., Borzacchiello, M. T., Bulgheroni, C., Camia, A., Fiore, G., Follador, M., Gurria, P., la Notte, A., Lusser, M., Marelli, L., M'Barek, R., Parisi, C., ... Mubareka, S. (2020). Development of a bioeconomy monitoring framework for the European Union: An integrative and collaborative approach. New Biotechnology, 59(July), 10 19. https://doi.org/10.1016/j.nbt.2020.06.001

18. Ronzon, T., \& M'Barek, R. (2018). Socioeconomic indicators to monitor the EU's bioeconomy in transition. Sustainability (Switzerland), 10(6). https://doi.org/10.3390/su10061745

19. SAT-BBE Cnsortium. (2013). Tools for evaluating and monitoring the EU bioeconomy: Indicators. Systems Analysis Tools Framework for the EU Bio-Based Economy Strategy

20. Woźniak, E,. \& Twardowski, T. (2018) The bioeconomy in Poland within the context of the European Union. In: New biotechnology no. 40, pp.96-102.

21. Zeug, W., Bezama, A., Moesenfechtel, U., Jähkel, A., \& Thrän, D. (2019). Stakeholders' interests and perceptions of bioeconomy monitoring using a sustainable development $\begin{array}{llll}\text { goal framework. } & \text { Sustainability } & \text { (Switzerland), } & 11(6) .\end{array}$ https://doi.org/10.3390/su11061511 